\title{
Phase 2 study of everolimus for relapsed or refractory classical Hodgkin lymphoma
}

(2) CrossMark

\author{
Patrick B. Johnston ${ }^{1 *}$, Lauren C. Pinter-Brown ${ }^{2}$, Ghulam Warsi ${ }^{3}$, Kristen White ${ }^{3}$ \\ and Radhakrishnan Ramchandren ${ }^{4}$
}

\begin{abstract}
Background: The current standard of care for classical Hodgkin lymphoma $(\mathrm{HL})$ is multiagent chemotherapy with or without radiation. In patients who relapse or fail to respond, additional high-dose chemotherapy with autologous hematopoietic stem cell transplantation (AHSCT) can improve progression-free survival (PFS). Novel therapies are required for patients refractory to chemotherapy and AHSCT. The mammalian target of rapamycin inhibitor everolimus has shown preliminary activity in preclinical models of $\mathrm{HL}$ and promising efficacy in patients with relapsed or refractory HL.
\end{abstract}

Methods: This was an open-label, two-stage, phase 2 study that enrolled 57 patients aged $\geq 18$ years with classic $\mathrm{HL}$ that had progressed after standard therapy. Patients received everolimus $10 \mathrm{mg}$ daily until disease progression, intolerable toxicity, withdrawal of consent, or investigator decision. The primary endpoint was overall response rate; secondary endpoints included PFS, overall survival, time to response, duration of response, and safety.

Results: Overall response rate was 45.6\% (95\% confidence interval [CI] 32.4-59.3\%); five patients (8.8\%) experienced a complete response and 21 patients had a partial response (36.8\%). Median PFS was 8.0 months ( $95 \% \mathrm{Cl} 5.1-$ 11.0 months). Seven patients (12\%) were long-term responders ( $\geq 12$ months). The most common study drug-related adverse events were thrombocytopenia (45.6\%), fatigue (31.6\%), anemia (26.3\%), rash (24.6\%), and stomatitis (22.8\%).

Conclusions: Everolimus $10 \mathrm{mg} /$ day demonstrated favorable results in patients with heavily pretreated, relapsed, or refractory classical $\mathrm{HL}$. These findings support the further evaluation of everolimus in this indication.

Trial registration ClinicalTrials.gov NCT01022996. Registered November 25, 2009

Keywords: Clinical trial, Everolimus, Hodgkin lymphoma, mTOR inhibitors, Relapsed/refractory

\section{Background}

In 2014 there were more than 9000 estimated new cases of Hodgkin lymphoma (HL) in the United States, and an estimated 1180 deaths were caused by the disease [1]. The highest incidence of new HL diagnoses occurred in patients between the ages of 20 and 34 years $[1,2]$. The 5 -year relative survival rate improved from approximately $70 \%$ in 1975 to just over $88 \%$ in 2006 [1]. The current standard of care for classical HL is systemic chemotherapy, with the main options being ABVD [Adriamycin ${ }^{\circledR}$

\footnotetext{
*Correspondence: johnston.patrick@mayo.edu

${ }^{1}$ Division of Hematology, Mayo Clinic, 200 First Street SW, Rochester, MN 55905, USA

Full list of author information is available at the end of the article
}

(doxorubicin), bleomycin, vinblastine, and dacarbazine], Stanford V (doxorubicin, vinblastine, mechlorethamine, etoposide, vincristine, bleomycin, and prednisone), or BEACOPP (bleomycin, etoposide, doxorubicin, cyclophosphamide, oncovin (vincristine), procarbazine, and prednisone), with or without the addition of radiotherapy [3]. For patients who do not respond to first-line treatment $(\approx 10 \%)$ or who relapse after experiencing initial response $(\approx 20 \%)$, high-dose chemotherapy with autologous hematopoietic stem cell transplantation (AHSCT) is the standard of care [3-6]. This salvage therapy has been shown to improve progression-free survival (PFS) and event-free survival $[4,7-9]$.

Patients whose disease is refractory to or relapses after high-dose chemotherapy with AHSCT have traditionally

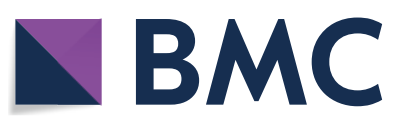

(c) The Author(s) 2018. This article is distributed under the terms of the Creative Commons Attribution 4.0 International License (http://creativecommons.org/licenses/by/4.0/), which permits unrestricted use, distribution, and reproduction in any medium, provided you give appropriate credit to the original author(s) and the source, provide a link to the Creative Commons license, and indicate if changes were made. The Creative Commons Public Domain Dedication waiver (http://creativecommons.org/ publicdomain/zero/1.0/) applies to the data made available in this article, unless otherwise stated. 
had limited treatment options, although a growing understanding of the biology of HL is leading to the development and testing of a wider range of novel therapeutic strategies $[6,10]$. Allogeneic hematopoietic stem cell transplantation (allogeneic HSCT) has been associated with very high treatment-related mortality rates and limited success, although there are case histories reporting long-term remission using this strategy [11]. Less toxic post-AHSCT therapies are urgently needed. The anti-CD30 antibody-drug conjugate brentuximab vedotin, which has shown benefit in patients with relapsed or refractory HL $[12,13]$, has been approved in the United States and Europe for the treatment of HL after failure of AHSCT or after failure of two or more previous multiagent chemotherapy regimens in patients who are not candidates for AHSCT [3]. In a phase 2 study in 102 patients with relapsed/refractory $\mathrm{HL}$, the overall response rate (ORR) for brentuximab vedotin was $75 \%$, with a disease control rate (DCR) of 96 and 34\% achieving complete response $(C R)$ [13]. In patients with a CR, the median PFS was 21.7 months [13]. Despite these encouraging results, the overall median PFS was only 5.6 months across the trial's entire patient population [13]. Moreover, as brentuximab vedotin is not considered to be curative therapy, all patients are expected to eventually relapse. More recently, immune checkpoint inhibitors (CPIs) targeting the programmed death pathway have been developed to reinstate anti-tumor immune responses [14], and two such agents (nivolumab and pembrolizumab) are now approved for the treatment of refractory HL $[3,15]$. Nivolumab is a treatment option for relapsed/refractory HL following HSCT, and pembrolizumab is an option for relapsed/refractory HL after $\geq 3$ prior lines of therapy [3]. However, accelerated approval granted for both of these agents was based on overall response rate and duration of response, and confirmatory data of their clinical benefit in refractory HL may be required $[16,17]$. Therefore, there remains an unmet need for additional therapeutic options to improve outcomes for more of these heavily pretreated patients.

The phosphatidylinositol 3-kinase (PI3K)/Akt/mammalian target of rapamycin (mTOR) pathway, a central regulator of cell growth, proliferation, survival, metabolism, and angiogenesis, is often dysregulated in HL [18-21]. Everolimus is an oral mTOR inhibitor that has demonstrated antitumor activity in refractory hematologic malignancies $[22,23]$ and in preclinical studies in both in vitro and in vivo models of HL [24]. In a phase 2 trial of inpatients with relapsed or refractory lymphomas treated with everolimus $10 \mathrm{mg}$ once daily, a subgroup of 19 patients with HL responded positively to treatment with everolimus, with an ORR of $47 \%(9 / 19)$, a median duration of response of 7.1 months, and median PFS and overall survival (OS) of 6.2 and 25.2 months, respectively [25]. Treatment was generally well tolerated; the most common grade $3 / 4$ adverse events (AEs) possibly related to everolimus were anemia (32\%), thrombocytopenia (32\%), dyspnea (10\%), and pneumonia (10\%) [25]. Following these promising results, the current prospective phase 2 trial was undertaken to confirm the efficacy and safety of everolimus in patients with relapsed or refractory HL.

\section{Methods \\ Patients}

The study enrolled patients aged $\geq 18$ years with classical HL that had progressed after high-dose chemotherapy with AHSCT (if eligible) and/or a gemcitabine-, vinorelbine-, or vinblastine-containing regimen. Patients were required to have an Eastern Cooperative Oncology Group performance status of $\leq 2$, at least one site of measurable disease, and adequate bone marrow, hepatic, and renal function. They also had to meet the following blood and chemistry measures: absolute neutrophil count $\geq 1.0 \times 10^{9} / \mathrm{L}$, platelet count $\geq 75 \times 10^{9} / \mathrm{L}$, serum creatinine $\leq 1.5 \times$ upper limit of normal (ULN), serum bilirubin $\leq 1.5 \times \mathrm{ULN}$, aspartate and alanine aminotransferase levels $\leq 2.5 \times$ ULN or $\leq 5.0 \times$ ULN if elevation is due to disease involvement, fasting cholesterol $\leq 300 \mathrm{mg} / \mathrm{dL}(\leq 7.75 \mathrm{mmol} / \mathrm{L})$, and fasting triglycerides $\leq 2.5 \times$ ULN. No concomitant anticancer therapy was permitted. Patients were ineligible for the trial if they had received any prior treatment with an mTOR inhibitor; if they were treated with a monoclonal antibody therapy, chemotherapy, any investigational drug, or radiation therapy, or if they had had major surgery within 4 weeks of starting everolimus. Patients were also not permitted to have had previous allogeneic HSCT nor any other severe or uncontrolled medical conditions.

\section{Study design and treatment}

This was a multicenter, open-label, single-arm, two-stage, phase 2 study conducted in the United States (ClinicalTrials.gov identifier NCT01022996, https://clinicaltrials. gov/ct2/show/NCT01022996). Everolimus was administered orally at a dose of $10 \mathrm{mg}$ once daily (at the same time every day, with or without food) until disease progression, intolerable toxicity, withdrawal of consent, or investigator decision. Dose adjustments and interruptions were permitted according to an algorithm outlined in the study protocol in the event of toxicity suspected to be related to everolimus.

All patients (or their legal representative) provided written informed consent before enrollment. The study was conducted in accordance with the ICH Good Clinical Practice Guidelines and the ethical principles specified 
in the Declaration of Helsinki. The protocol and consent forms were reviewed and approved by the appropriate ethics body of each institution before study initiation.

\section{Efficacy and safety evaluations}

Tumor assessments were performed at baseline using integrated positron emission tomography (PET)/ computed tomography $(\mathrm{CT})$ with contrast and every 12 weeks (3 cycles) thereafter using integrated PET/CT with contrast or $\mathrm{CT}$ with intravenous contrast. In the event of CR or partial response (PR), respectively, a confirmatory scan was performed 4 or more weeks after the response was first documented.

The primary study endpoint was ORR. Secondary endpoints included DCR, PFS, OS, time to overall response, duration of overall response, and duration of disease control. Safety was assessed by monitoring and recording all AEs and regularly monitoring hematology, serum chemistry, and physical condition. Toxicity was assessed according to the National Cancer Institute Common Terminology Criteria for Adverse Events, version 3.0.

\section{Statistics}

The trial used a Simon two-stage MinMax design [26]. The trial required enrollment of 54 eligible patients to test the null hypothesis that the true ORR for everolimus is $\leq 15 \%$ versus the alternative hypothesis that the true ORR is $\geq 30 \%$. The study had $85 \%$ power with a one-sided type I error rate of $5 \%$. Stage 1 was to enroll 39 patients; if $\leq 7$ confirmed responses were noted, the trial was to be discontinued. If $\geq 8$ confirmed responses were observed among the first 39 patients, an additional 15 patients were to be enrolled in stage 2 .

Efficacy analyses were performed using the full analysis set of patients, defined as all patients who received at least one dose of study drug. The safety assessment was performed on the safety population, defined as all enrolled patients who received at least one dose of study drug and had at least one postbaseline safety assessment.

Exact 95\% confidence intervals (CIs) were calculated for ORR and DCR. Progression-free survival, OS, duration of response, and duration of disease control were estimated using the Kaplan-Meier method. ORR was defined as the percentage of patients who achieved confirmed CR or PR within 32 weeks of everolimus initiation as determined by CT scan using modified response criteria for malignant lymphoma, adapted from Cheson et al. [27]. PFS was defined as the time from start of treatment to the date of documented disease progression, death from any cause, or start of new anticancer therapy. OS was defined as the time from start of treatment to the date of death from any cause. DCR was defined as the percentage of patients who achieved a best overall response of CR, PR, or stable disease, and duration of disease control was defined as the time from start of treatment to the date of documented disease progression, death from any cause, or start of new anticancer therapy in patients who experienced CR, PR, or stable disease. Time to overall response was measured as the time from the start of treatment to the first documented response, and duration of overall response was defined as the time from the first documented response to the date of documented disease progression, death from any cause, or start of new anticancer therapy. Patients who were still receiving treatment at the time of the data analysis were censored at the date of the last adequate tumor assessment.

\section{Results}

\section{Patient characteristics}

A total of 57 patients from 14 centers were enrolled between December 22, 2009, and November 24, 2014. The study ran until November 28, 2014, when the last patient discontinued (i.e., completed the study). Reasons for treatment end were disease progression $(n=32)$, AEs $(n=14)$, withdrawal of consent $(n=3)$, administrative problems $(n=6)$, and protocol deviation or lost to follow-up ( $n=1$ each). Eleven patients completed the study follow-up phase according to protocol.

Patient demographics and baseline disease characteristics are summarized in Table 1 . The median patient age was 32.0 years, $58 \%$ of patients were female, and $77 \%$ were white. Previous therapy included a gemcitabine-, vinorelbine-, or vinblastine-containing regimen in $100 \%$ of patients and AHSCT in $67 \%$ of patients. In addition, 15 patients $(26.3 \%)$ received prior brentuximab vedotin, with CR and PR being achieved by three patients each (duration of response ranging from 1 to 11 months). Two-thirds of patients had experienced disease progression during previous therapy.

\section{Efficacy}

The ORR was $45.6 \%$ ( $n=26 / 57$; $95 \%$ CI $32.4-59.3 \%$ ); five patients experienced a CR (8.8\%) and 21 experienced a PR (36.8\%) (Table 2). An additional 20 patients (35.1\%) experienced disease stabilization, indicating a DCR of $80.7 \%$. Median duration of response was 7.3 months (range 1 day-4.2 years). Median PFS was 7.3 months (95\% CI 4.7-10.1 months) (Fig. 1). Median OS was not reached (Fig. 2); 45 patients were still alive (78.9\%) at the time of analysis.

Seven patients had a response duration of $\geq 1$ year (i.e., long-term responders) (Table 3). Best response for these patients included two CRs and five PRs. Two patients experienced prolonged stable disease prior to response (1.8 years before CR and 1.2 years before PR, 
Table 1 Baseline demographics and disease characteristics

\begin{tabular}{|c|c|}
\hline Characteristic, n (\%) & $N=57$ \\
\hline Age, years, median (range) & $32.0(19.0-77.0)$ \\
\hline \multicolumn{2}{|l|}{ Sex, n (\%) } \\
\hline Male & $24(42.1)$ \\
\hline Female & $33(57.9)$ \\
\hline \multicolumn{2}{|l|}{ Race, n (\%) } \\
\hline White & $44(77.2)$ \\
\hline Black or African American & $8(14.0)$ \\
\hline Asian & $1(1.8)$ \\
\hline Pacific Islander & $3(5.3)$ \\
\hline Other & $1(1.8)$ \\
\hline \multicolumn{2}{|l|}{ ECOG performance status, n (\%) } \\
\hline 0 & $32(56.1)$ \\
\hline 1 & $23(40.4)$ \\
\hline 2 & $2(3.5)$ \\
\hline \multicolumn{2}{|l|}{ Hodgkin lymphoma classification, n (\%) } \\
\hline Classical nodular sclerosis & $52(91.2)$ \\
\hline Classical mixed cellularity & $3(5.3)$ \\
\hline Other & $2(3.5)$ \\
\hline \multicolumn{2}{|l|}{ Stage at diagnosis, n (\%) } \\
\hline । & $2(3.5)$ \\
\hline$\|$ & $20(35.1)$ \\
\hline III & $18(31.6)$ \\
\hline IV & $17(29.8)$ \\
\hline Number of previous regimens, median (range) & $4(1-17)$ \\
\hline \multicolumn{2}{|l|}{ Previous treatment, $\mathrm{n}(\%)$} \\
\hline AHSCT & $38(66.7)$ \\
\hline Gemcitabine-containing regimen & $32(56.1)$ \\
\hline Vinorelbine-containing regimen & $23(40.4)$ \\
\hline Vinblastine-containing regimen & $55(96.5)$ \\
\hline Disease progression during previous therapy, n (\%) & $38(66.7)$ \\
\hline $\begin{array}{l}\text { Time from diagnosis to first recurrence/relapse, } \\
\text { months, median (range) }\end{array}$ & $11.1(0.6-80.0)$ \\
\hline $\begin{array}{l}\text { Time from diagnosis to most recent recurrence/ } \\
\text { relapse, months, median (range) }\end{array}$ & $38.9(7.0-221.4)$ \\
\hline
\end{tabular}

Unless otherwise noted, all data are presented as $\mathrm{n}(\%)$

AHSCT autologous hematopoietic stem cell transplantation, ECOG Eastern Cooperative Oncology Group

Table 2 Best overall response to everolimus treatment

\begin{tabular}{lc}
\hline Best overall response, $\mathbf{n}(\%)$ & $\mathbf{N}=\mathbf{5 7}$ \\
\hline Complete response & $5(8.8)$ \\
Partial response & $21(36.8)$ \\
Stable disease & $20(35.1)$ \\
Progressive disease & $9(15.8)$ \\
Unknown & $2(3.5)$ \\
\hline
\end{tabular}

respectively), and one patient had a prolonged PR followed by CR (over 3 years in total). One patient with a PR has been on everolimus therapy for 4.7 years.

\section{Safety}

Three patients died from their cancer during the study. The median duration of exposure to everolimus was 4.1 months (range 1 day-4.7 years). Nearly a quarter of patients $(22.8 \%)$ received everolimus for more than 13 months. Dose reductions were required in 35 patients (61.4\%), and 31 patients (54.4\%) experienced dose interruptions. AEs, which were the most common reason for dose adjustment, were experienced by 30 patients $(52.6 \%)$; laboratory test abnormalities led to dose adjustments in an additional $14 \%$ of patients.

All but one patient experienced at least one $\mathrm{AE}$ of any grade during the study (Table 4 ). Grade $3 / 4$ AEs occurred in 35 patients (61.4\%). The most common AEs were fatigue $(57.9 \%)$, thrombocytopenia (49.1\%), and cough (49.1\%); most were grade $1 / 2$ in severity $(100,57.1$, and $96.4 \%$, respectively). Stomatitis was experienced by $24.6 \%$ of patients, but was of grade $3 / 4$ in only $3.5 \%$ of patients. Pneumonitis was observed in six patients (10.5\%) and was of grade 1 in one patient $(1.8 \%)$ and grade 2 in five patients $(8.8 \%)$; no patients experienced grade $3 / 4$ pneumonitis. No grade 4 hyperglycemia, hypercholesterolemia, or hypertriglyceridemia events were observed. Serious AEs were experienced by 18 (31.6\%) patients. Serious AEs occurring in more than one patient included pneumonia in four patients (grade $2, n=1$; grade $3, n=3$ ), pyrexia in three patients (grade $1, n=1$; grade $2, n=2$ ), anemia in two patients (grade $1, n=1$; grade $4, n=1$ ), pleural effusion in two patients (grade $2, n=1$; grade $3, n=1$ ), tachycardia in two patients (grade $1, n=1$; grade 2, $n=1$ ), and hypotension in two patients (grade $1, n=1$; grade $2, n=1$ ).

The most common AEs (>20\%) considered to be related to study drug administration were thrombocytopenia ( $45.6 \%$ overall; $21.1 \%$ grade $3 / 4$ ), fatigue $(31.6 \%$ overall; $0 \%$ grade $3 / 4)$, anemia ( $26.3 \%$ overall; $12.3 \%$ grade $3 / 4)$, rash (24.6\% overall; $1.8 \%$ grade $3 / 4)$, and stomatitis (22.8\% overall; $3.5 \%$ grade $3 / 4)$. AEs that led to permanent study drug discontinuation in more than one patient included thrombocytopenia in four patients (7.0\%) and dyspnea and pyrexia in two patients (3.5\%) each. Overall, $54.4 \%$ of patients had an AE that required study drug dose adjustment or interruption; the most common AEs were thrombocytopenia (19.3\%), neutropenia (8.8\%), 


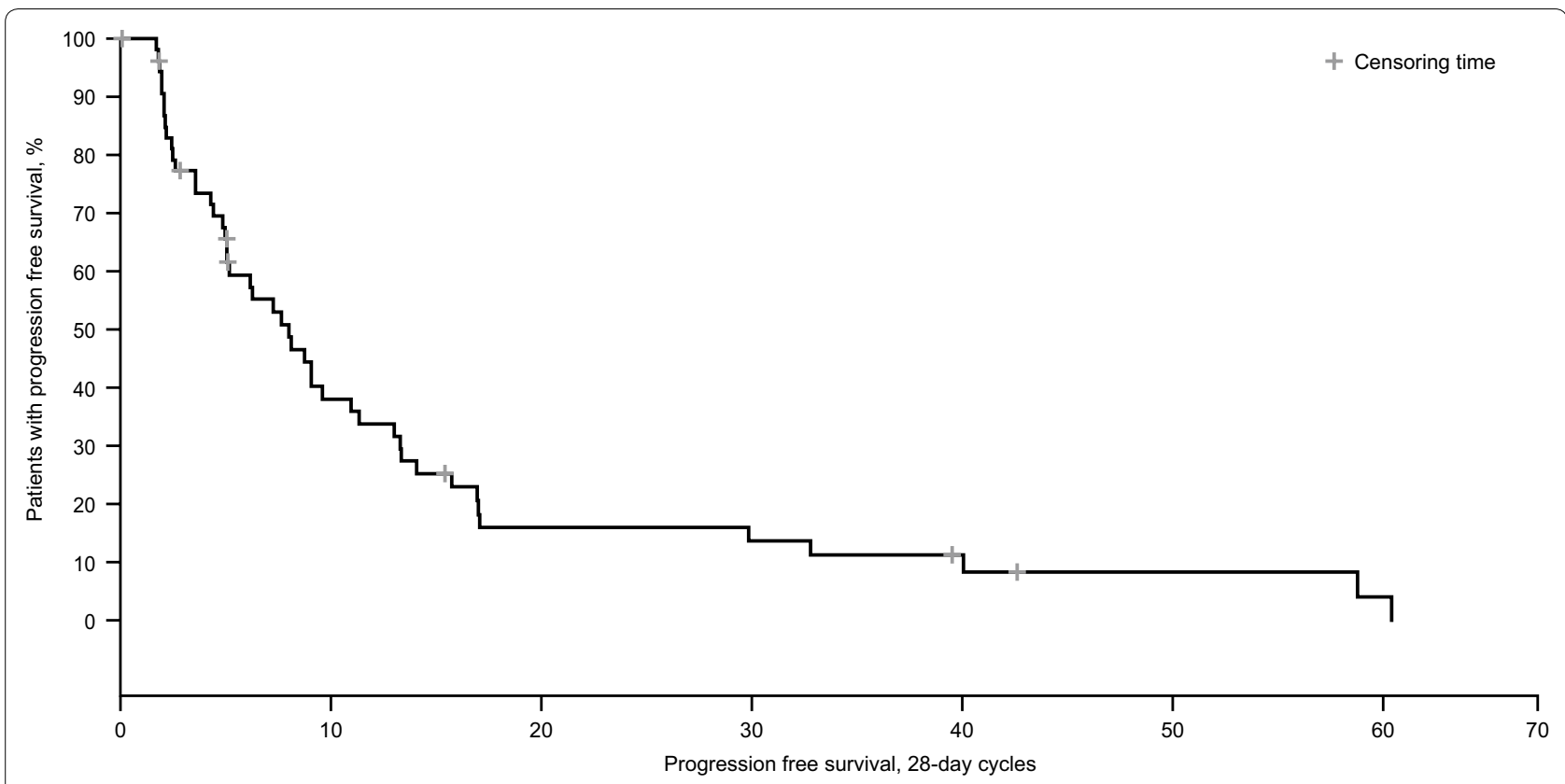

Fig. 1 Kaplan-Meier estimate of progression-free survival

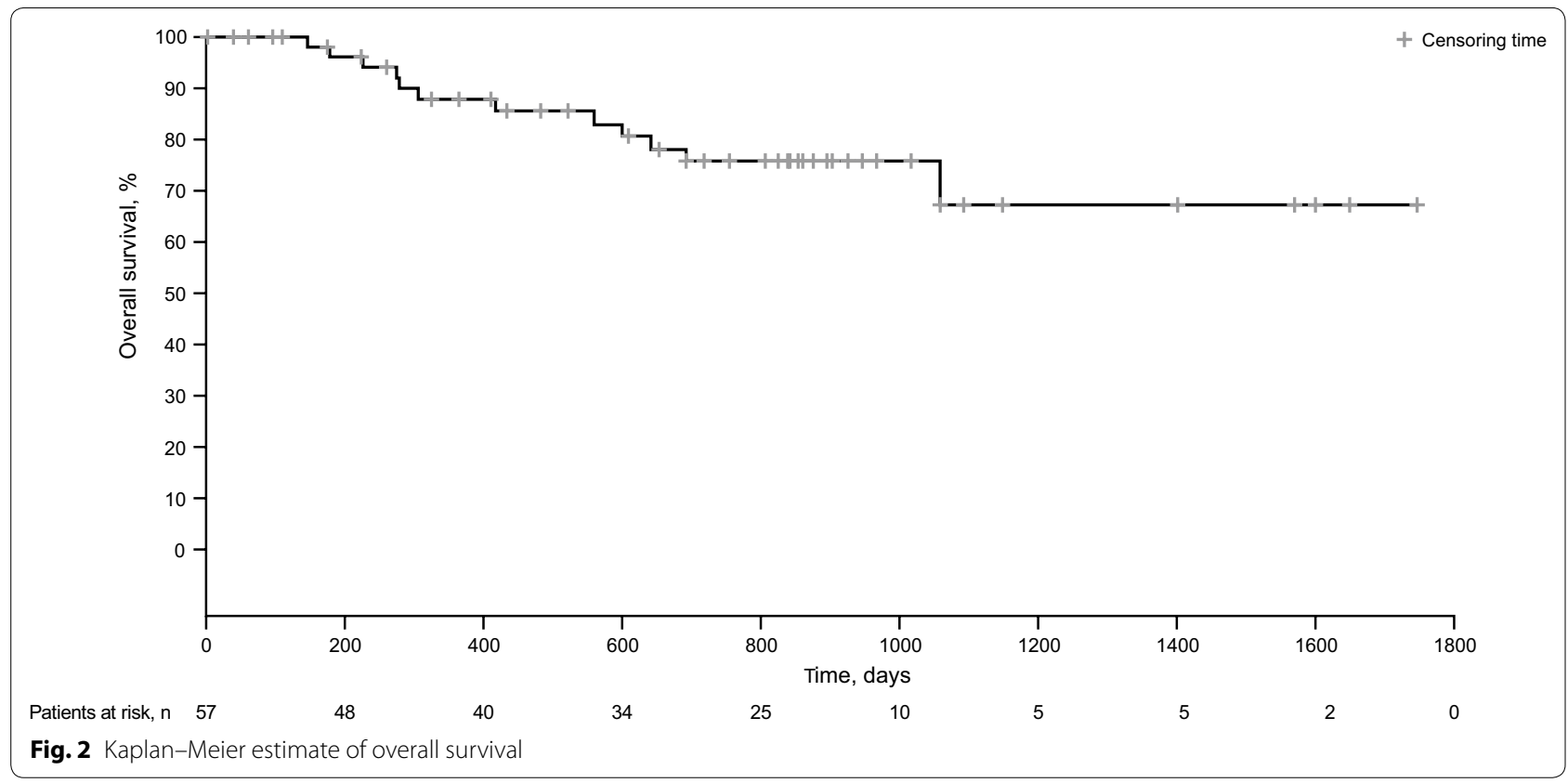

anemia (7.0\%), and hypophosphatemia (7.0\%). Only one case $(1.8 \%)$ of grade 2 pneumonitis required adjustment or interruption of study drug dose.

\section{Discussion}

Everolimus $10 \mathrm{mg}$ once daily provided a favorable ORR of $45.6 \%$ and a median PFS of 7.3 months in patients with heavily pretreated, relapsed, or refractory classical HL.
The ORR of nearly $46 \%$ is similar to the $47 \%$ reported for patients with HL in a phase 2 study of everolimus monotherapy in rare lymphomas [25]. The DCR of $80.7 \%$ is a positive finding in this heavily pretreated patient population, which had a median of four previous treatments. Despite the ORR in this study being considerably lower than that reported for brentuximab vedotin in a single-arm phase 2 trial (ORR 75\%), the PFS was 
Table 3 Detailed information on long-term responders to everolimus

\begin{tabular}{|c|c|c|c|c|c|c|}
\hline \multirow[t]{2}{*}{ Patient } & \multicolumn{2}{|l|}{ Previous therapy } & \multicolumn{4}{|l|}{ Everolimus } \\
\hline & $\begin{array}{l}\text { Systemic therapy (best } \\
\text { response) }\end{array}$ & Other & $\begin{array}{l}\text { Treatment } \\
\text { duration, } \\
\text { years }\end{array}$ & Best response & Current response (date) & $\begin{array}{l}\text { Response } \\
\text { duration, } \\
\text { years }\end{array}$ \\
\hline White male, aged 64 years & $\begin{array}{l}\text { 1. ABVD (UNK) } \\
\text { 2. ICE (UNK) }\end{array}$ & $\begin{array}{l}\text { Radiotherapy } \\
\text { ASCT }\end{array}$ & 4.7 & $P R$ & PD (August 8, 2014) & 4.2 \\
\hline $\begin{array}{l}\text { White female, aged } \\
28 \text { years }\end{array}$ & $\begin{array}{l}\text { 1. ABVD (PR) } \\
\text { 2. ICE (PR) } \\
\text { 3. DHAP (PR) }\end{array}$ & $\begin{array}{l}\text { Radiotherapy } \\
\text { ASCT }\end{array}$ & 3.9 & $P R$ & PD (October 28, 2014) & 3.5 \\
\hline Asian female, aged 28 years & $\begin{array}{l}\text { 1. } A B \vee D(P R) \\
\text { 2. ICE (PR) }\end{array}$ & Radiotherapy & 2.5 & $P R$ & PD (November 5, 2013) & 2.2 \\
\hline $\begin{array}{l}\text { White female, aged } \\
36 \text { years }\end{array}$ & $\begin{array}{l}\text { 1. ABVD (PR) } \\
\text { 2. ICE (NA) } \\
\text { 3. CBV (NA) } \\
\text { 4. Panobinostat (stable } \\
\text { disease) }\end{array}$ & $\begin{array}{l}\text { Radiotherapy } \\
\text { ASCT }(\times 2)\end{array}$ & 4.5 & $C R$ & PD (November 24, 2014) & $2.3^{\mathrm{a}}$ \\
\hline White male, aged 39 years & $\begin{array}{l}\text { 1. } A B V D(C R) \\
\text { 2. ICE (CR) }\end{array}$ & $\begin{array}{l}\text { Radiotherapy } \\
\text { ASCT }\end{array}$ & 3.8 & $C R$ & Unknown (October 8, 2014) & $3.7^{b}$ \\
\hline White male, aged 40 years & $\begin{array}{l}\text { 1. } A B V D(P R) \\
\text { 2. ICE (NA) } \\
\text { 3. GVD (NA) } \\
\text { 4. SWOG protocol } 14110 \\
\text { (CR) } \\
\text { 5. Brentuximab (stable } \\
\text { disease) } \\
\text { 6. HDAC inhibitor (UNK) }\end{array}$ & $\begin{array}{l}\text { Radiotherapy } \\
\mathrm{ASCT}(\times 2)\end{array}$ & 3.1 & $P R$ & PD (May 27, 2014) & $1.8^{\mathrm{a}}$ \\
\hline $\begin{array}{l}\text { White female, aged } \\
27 \text { years }\end{array}$ & $\begin{array}{l}\text { 1. ABVD (PR) } \\
\text { 2. ICE (PR) } \\
\text { 3. Mini-BEAM (NA) } \\
\text { 4. Brentuximab (stable } \\
\text { disease) } \\
\text { 5. Lenalidomide (stable } \\
\text { disease) }\end{array}$ & $\begin{array}{l}\text { Radiotherapy } \\
\text { ASCT }\end{array}$ & 4.0 & $P R$ & $\begin{array}{l}\text { Unknown (September } 4 \text {, } \\
\text { 2014) }\end{array}$ & 1.0 \\
\hline
\end{tabular}

ABVD Adriamycin (doxorubicin), bleomycin, vinblastine, and dacarbazine, AHSCT autologous hematopoietic stem cell transplantation, $C B V$ cyclophosphamide, carmustine, etoposide, $C R$ complete response, DHAP rituximab, dexamethasone, cytarabine, cisplatin, GVD gemcitabine, vinorelbine, doxil, $H D A C$ histone deacetylase, ICE ifosfamide, carboplatin, etoposide, mini-BEAM carmustine, etoposide, cytarabine, melphalan, $P D$ progressive disease, $P R$ partial response, SWOG southwest oncology group, UNK unknown

a Prior to response, patient experienced prolonged stable disease

b Duration of both CR and PR

encouragingly longer with everolimus (8.0 months) than the 5.6 months reported for brentuximab in patients with CD30+ relapsed or refractory HL following high-dose chemotherapy with AHSCT [13]. A pivotal phase 2 study in heavily pretreated patients receiving brentuximab vedotin also reported a substantially higher ORR (72\%), an overall median PFS of 9.3 months (53.3 months in patients who had achieved CR), and a median duration of response of 33.3 months [28].

It should be noted that ORR was evaluated by $\mathrm{CT}$ scan in the current study due to uncertainties regarding the effect of everolimus on glucose metabolism and, as a consequence, PET interpretation [6]. Due to the fact that patients with HL may have metabolically inactive residual masses posttreatment [6], it is possible that some PRs may reflect complete metabolic resolution, which may have resulted in the underestimation of ORR. Therefore, further study is necessary to evaluate this phenomenon. In addition, the 2007 recommendations for staging and assessment of treatment response in patients with and without HL were recently updated, providing new definitions of CR, PR, and progressive disease [29]. In particular, CR may be achieved in the presence of a mass that is no longer avid (i.e., one that has achieved complete metabolic response), PR may be confirmed by up to six representative nodes or extranodal lesions, and the determination of progressive disease only requires a single node [29]. Therefore, combining the improved use and interpretation of PET data along with the most recent standardized response criteria may have adjusted the assessment of response to everolimus in the current study, and thus a potentially higher ORR.

In this study, a number of patients had response durations of $\geq 1$ year while being treated with everolimus on 
Table 4 Adverse events of any cause that were experienced by $>10 \%$ of patients $(N=57)$

\begin{tabular}{|c|c|c|c|}
\hline $\mathrm{AE}$ & Any grade & Grade $1 / 2$ & Grade $3 / 4$ \\
\hline Any & $56(98.2)$ & $21(36.8)$ & $35(61.4)$ \\
\hline Fatigue & $33(57.9)$ & $33(57.9)$ & 0 \\
\hline Thrombocytopenia & $28(49.1)$ & $16(28.1)$ & $12(21.1)$ \\
\hline Cough & $28(49.1)$ & $27(47.4)$ & $1(1.8)$ \\
\hline Rash & $22(38.6)$ & $21(36.8)$ & $1(1.8)$ \\
\hline Anemia & $19(33.3)$ & $11(19.3)$ & $8(14.0)$ \\
\hline Pyrexia & $19(33.3)$ & $19(33.3)$ & 0 \\
\hline Dyspnea & $17(29.8)$ & $14(24.6)$ & $3(5.3)$ \\
\hline Back pain & $16(28.1)$ & $14(24.6)$ & $2(3.5)$ \\
\hline Diarrhea & $16(28.1)$ & $15(26.3)$ & $1(1.8)$ \\
\hline Stomatitis & $14(24.6)$ & $12(21.1)$ & $2(3.5)$ \\
\hline Upper respiratory tract infection & $14(24.6)$ & $13(22.8)$ & $1(1.8)$ \\
\hline Headache & $13(22.8)$ & $12(21.1)$ & $1(1.8)$ \\
\hline Nausea & $14(24.6)$ & $14(24.6)$ & 0 \\
\hline Vomiting & $13(22.8)$ & $13(22.8)$ & 0 \\
\hline Peripheral edema & $12(21.1)$ & $12(21.1)$ & 0 \\
\hline Hyperglycemia & $10(17.5)$ & $7(12.3)$ & $3(5.3)$ \\
\hline Pruritus & $12(21.1)$ & $12(21.1)$ & 0 \\
\hline Abdominal pain & $9(15.8)$ & $9(15.8)$ & 0 \\
\hline Arthralgia & $9(15.8)$ & $9(15.8)$ & 0 \\
\hline $\begin{array}{l}\text { Aspartate aminotransferase } \\
\text { increased }\end{array}$ & $9(15.8)$ & $8(14.0)$ & $1(1.8)$ \\
\hline Muscle spasms & $9(15.8)$ & $9(15.8)$ & 0 \\
\hline Neuropathy peripheral & $9(15.8)$ & $9(15.8)$ & 0 \\
\hline Oropharyngeal pain & $11(19.3)$ & $11(19.3)$ & 0 \\
\hline Acne & $8(14.0)$ & $8(14.0)$ & 0 \\
\hline Alanine aminotransferase increased & $8(14.0)$ & $7(12.3)$ & $1(1.8)$ \\
\hline Dysgeusia & $8(14.0)$ & $8(14.0)$ & 0 \\
\hline Epistaxis & $8(14.0)$ & $8(14.0)$ & 0 \\
\hline Neutropenia & $8(14.0)$ & $3(5.3)$ & $5(8.8)$ \\
\hline Pain & $8(14.0)$ & $7(12.3)$ & $1(1.8)$ \\
\hline Pain in extremity & $8(14.0)$ & $7(12.3)$ & $1(1.8)$ \\
\hline Sinusitis & $10(17.5)$ & $10(17.5)$ & 0 \\
\hline $\begin{array}{l}\text { Blood alkaline phosphatase } \\
\text { increased }\end{array}$ & $9(15.8)$ & $7(12.3)$ & $2(3.5)$ \\
\hline Bronchitis & $7(12.3)$ & $7(12.3)$ & 0 \\
\hline Hypertriglyceridemia & $7(12.3)$ & $5(8.8)$ & $2(3.5)$ \\
\hline Pneumonia & $7(12.3)$ & $3(5.3)$ & $4(7.0)$ \\
\hline $\begin{array}{l}\text { Blood lactate dehydrogenase } \\
\text { increased }\end{array}$ & $6(10.5)$ & $6(10.5)$ & 0 \\
\hline Decreased appetite & $7(12.3)$ & $7(12.3)$ & 0 \\
\hline Hypercholesterolemia & $6(10.5)$ & $6(10.5)$ & 0 \\
\hline Hypokalemia & $6(10.5)$ & $5(8.8)$ & $1(1.8)$ \\
\hline Hypophosphatemia & $7(12.3)$ & $2(3.5)$ & $5(8.8)$ \\
\hline Insomnia & $6(10.5)$ & $6(10.5)$ & 0 \\
\hline Night sweats & $6(10.5)$ & $6(10.5)$ & 0 \\
\hline Pleural effusion & $6(10.5)$ & $4(7.0)$ & $2(3.5)$ \\
\hline Pneumonitis & $6(10.5)$ & $6(10.5)$ & 0 \\
\hline Weight decreased & $7(12.3)$ & $7(12.3)$ & 0 \\
\hline
\end{tabular}

$A E$ adverse event study for 2-3 years. Patients did not need to have a CR to everolimus to derive long-term positive outcomes, and a number of patients were stable on everolimus for long periods of time without disease progression. To date, there has been no evidence of a unique clinical or biologic marker that can identify patients who may derive long-term benefit with everolimus.

Everolimus was generally well tolerated, with the majority of AEs being of grade $1 / 2$ severity and manageable without everolimus discontinuation. The need to reduce everolimus dose in approximately $60 \%$ of the patients could reflect the fact that these patients were heavily pretreated. Several of the most commonly reported AEs thought to be related to everolimus treatment (fatigue, stomatitis, rash) are consistent with those reported in previous studies of everolimus in oncology indications [30,31]. Appropriate management strategies for preventing and treating recognized AEs associated with mTOR inhibitors as a class in both oncology and immunosuppressive settings (e.g., stomatitis, rash, pneumonitis) have been well described previously [30-32]. In the current study, all cases of pneumonitis (10.5\%) were grade $1 / 2$, with only one grade 2 event requiring recommended active management comprising adjustment or interruption of study drug dose. However, prior clinical experience of AEs associated with everolimus in patients with hematologic malignancies is not extensive, so the findings of the present trial are useful to add breadth to the current database of knowledge. In an earlier phase 2 trial in patients with lymphomas, the main grade $3 / 4 \mathrm{AEs}$ reported in the HL subgroup were hematologic, primarily thrombocytopenia and anemia (32\% each), and pulmonary, including dyspnea and pneumonia (10.5\% each) [25].

In current treatment guideline recommendations for classical HL, everolimus is a subsequent systemic therapy option following second-line therapy with platinum- or gemcitabine-based chemotherapeutic regimens or brentuximab vedotin with or without platinum- or gemcitabine-based regimens [3]. Other subsequent systemic treatment options include lenalidomide, various chemotherapeutic regimens, the CPIs nivolumab (for relapsed or refractory classical HL after HSCT) and pembrolizumab (for relapsed or refractory classical HL after $\geq 3$ prior lines of therapy), or second-line treatment options not previously used. Everolimus is currently in early phase testing in relapsed or refractory $\mathrm{HL}$ as combination therapy with lenalidomide (NCT01075321), and rituximab, dexamethasone, cytarabine, cisplatin (DHAP; NCT01453504), and an ongoing phase 2 trial is evaluating everolimus plus rituximab as maintenance therapy following high-dose chemotherapy in lymphomas (including HL; NCT01665768). In addition, we have 
initiated a combination trial of everolimus plus brentuximab vedotin (NCT02254239) in patients with relapsed/ refractory Hodgkin lymphoma based on promising synergy in preclinical models (data not shown). Results from these everolimus combination studies are expected from late 2018, and may change the role of everolimus treatment in HL.

\section{Conclusions}

In summary, this phase 2 trial demonstrated that everolimus monotherapy can produce a favorable ORR and median PFS in heavily pretreated patients with relapsed or refractory classical HL. The overall safety profile was consistent with that previously observed for everolimus in patients with HL and other cancers. In the setting of heavily pretreated, relapsed, or refractory HL, several novel agents (panobinostat, AFM13, nivolumab, and lenalidomide) have recently been evaluated with preliminary evidence of response [33-36]. Studies of brentuximab vedotin in a similar setting have also shown some evidence of efficacy in this population [13, 28]. In the current study, treatment with everolimus provided durable responses in a subset of patients. Therefore, the overall positive clinical outcomes for many patients in this study confirm previous findings and support further evaluation of everolimus in patients with classical HL.

\footnotetext{
Abbreviations

ABVD: Adriamycin ${ }^{\circledR}$ (doxorubicin), bleomycin, vinblastine, and dacarbazine; AE: adverse event; AHSCT: autologous hematopoietic stem cell transplantation; BEACOPP: bleomycin, etoposide, doxorubicin, cyclophosphamide, oncovin (vincristine), procarbazine, and prednisone; Cl: confidence interval; CR: complete response; CT: computed tomography; DCR: disease control rate; $\mathrm{HL}$ : Hodgkin lymphoma; mTOR: mammalian target of rapamycin; ORR: overall response rate; OS: overall survival; PET: positron emission tomography; PFS: progression-free survival; PI3K: phosphatidylinositol 3-kinase; PR: partial response; ULN: upper limit of normal.
}

\section{Authors' contributions}

$\mathrm{PBJ}$ and GW substantially contributed to the conception and design of this study. PBJ, LPB, GW, and RR were responsible for data acquisition. GW provided statistical analysis. PBJ, LPB, JWR, GW, KW, RS, and RR were responsible for data interpretation. All authors provided critical revision of the manuscript for important intellectual content. All authors read and approved the final manuscript.

\section{Author details}

${ }^{1}$ Division of Hematology, Mayo Clinic, 200 First Street SW, Rochester, MN 55905, USA. ${ }^{2}$ Department of Hematology/Oncology, David Geffen School of Medicine at UCLA, Los Angeles, CA, USA. ${ }^{3}$ Department of Oncology, Novartis Pharmaceuticals Corporation, East Hanover, NJ, USA. ${ }^{4}$ Department of Hematology/Oncology, Karmanos Cancer Institute, Detroit, MI, USA.

\section{Acknowledgements \\ Editorial support was provided by Traci Stuve, of ApotheCom (Yardley, PA). Ghulam Warsi is no longer employed by Novartis, but he was an employee at the time that this research was conducted.}

\section{Competing interests}

PBJ served on an advisory board for Novartis. RS and KW are employees of Novartis. GW was an employee of Novartis at the time that this research was conducted; he has stocks, stock options, or bond holdings with Novartis. LCPB and RR have nothing to disclose.

\section{Availability of data and materials}

The data that support the findings of this study are available from Novartis but restrictions apply to the availability of these data, which were used under license for the current study, and so are not publicly available. Data are however available from the authors upon reasonable request and with permission of Novartis.

\section{Consent for publication \\ Not applicable.}

\section{Ethics approval and consent to participate}

The protocol and consent forms were reviewed and approved by the appropriate ethics body of each institution before study initiation (see "Appendix: Table $5^{\prime \prime}$ ). Informed consent was obtained from each patient in writing at Screening/Baseline before conducting any study-specific procedures. The study was described by the study coordinator or investigator, who answered any questions, and written information was also provided.

\section{Funding}

Funding was provided by Novartis Pharmaceuticals Corporation.

\section{Appendix}

See Table 5. 
Table 5 List of Independent Ethics Committees (IEC) or Institutional Review Boards (IRB) by study center

\begin{tabular}{|c|c|c|c|}
\hline Center no. & Ethics Committee or Institutional Review Board & Department/Organization & $\begin{array}{l}\text { City, State/Province, } \\
\text { Postal Code Country }\end{array}$ \\
\hline 501 & Mayo Clinical Institutional Review Boards & & Rochester, MN 55905 \\
\hline 502 & The University of Texas/MD Anderson Cancer Center & Office of Protocol Research & Houston, TX 77030 \\
\hline 503 & UCLA OHRPP & Office of Human Research Protection Program & Los Angeles, CA 90095 \\
\hline 504 & Dana Farber Cancer Institute & Office for Human Research Studies & Boston, MA 02215 \\
\hline 505 & Northwestern University & Office for the Protection of Research Subjects & Chicago, IL 60611 \\
\hline 506 & WIRB (Western Institutional Review Board) & & Olympia, WA 98508 \\
\hline 511 & Rush University Medical Center & Research \& Clinical Trials Administration Office & Chicago, IL 60612 \\
\hline 512 & MD Anderson Cancer Center/Orlando & Office of Protocol Research & Orlando, FL 32828 \\
\hline 513 & Wayne State University & Human Investigation Committee & Detroit, Ml 48201 \\
\hline 514 & Quorum Review IRB & & Seattle, WA 98101 \\
\hline 515 & Medical College of Wisconsin & Institutional Review Board & Milwaukee, WI 53226 \\
\hline 516 & WIRB (Western Institutional Review Board) & & Olympia, WA 98101 \\
\hline 517 & Duke University & Duke University Health System IRB & Durham, NC \\
\hline 519 & Washington University & Human Research Protection Office & St. Louis, MO 63110 \\
\hline 521 & $\begin{array}{l}\text { MedStar Health Research Institute-Georgetown } \\
\text { University }\end{array}$ & & Washington, DC 20057 \\
\hline 522 & Emory University & $\mathrm{IRB}$ & Atlanta, GA 30322 \\
\hline 523 & Weill Cornell Medical College & Human Research Protection Services & New York, NY 10065 \\
\hline 524 & IUPUI/Clarian Institutional Review Board & & Indianapolis, IN \\
\hline 525 & Oregon Health \& Science University & Research Integrity Office & Portland, OR 97239 \\
\hline
\end{tabular}

\section{Publisher's Note}

Springer Nature remains neutral with regard to jurisdictional claims in published maps and institutional affiliations.

Received: 30 January 2018 Accepted: 24 April 2018

Published online: 11 May 2018

\section{References}

1. National Cancer Institute. Cancer stat facts: Hodgkin lymphoma. 2013. http://seer.cancer.gov/statfacts/html/hodg.html. Accessed 13 Jan 2017.

2. National Cancer Institute. SEER cancer statistics review, 1975-2010. https://seer.cancer.gov/archive/csr/1975_2010. Updated 14 June 2013. Accessed 13 Jan 2017

3. National Comprehensive Cancer Network. Hodgkin Lymphoma (Version 3.2018). https://www.nccn.org/professionals/physician_gls/pdf/hodgk ins.pdf. Accessed 9 May 2018.

4. Kuruvilla J, Keating A, Crump M. How I treat relapsed and refractory Hodgkin lymphoma. Blood. 2011;117:4208-17.

5. Eichenauer DA, Engert A, Dreyling M, ESMO Guidelines Working Group. Hodgkin's lymphoma: ESMO clinical practice guidelines for diagnosis, treatment and follow-up. Ann Oncol. 2011;22(suppl 6):vi55-8.

6. Ramchandren R. Advances in the treatment of relapsed or refractory Hodgkin's lymphoma. Oncologist. 2012;17:367-76.

7. Linch DC, Winfield D, Goldstone AH, Moir D, Hancock B, McMillan A, et al. Dose intensification with autologous bone-marrow transplantation in relapsed and resistant Hodgkin's disease: results of a BNLI randomised trial. Lancet. 1993;341:1051-4.

8. Schmitz N, Pfistner B, Sextro M, Sieber M, Carella AM, Haenel M, et al. Aggressive conventional chemotherapy compared with high-dose chemotherapy with autologous haemopoietic stem-cell transplantation for relapsed chemosensitive Hodgkin's disease: a randomised trial. Lancet. 2002;359:2065-71.
9. Gutierrez-Delgado F, Holmberg L, Hooper H, Petersdorf S, Press O, Maziarz $R$, et al. Autologous stem cell transplantation for Hodgkin's disease: busulfan, melphalan and thiotepa compared to a radiation-based regimen. Bone Marrow Transplant. 2003;32:279-85.

10. Currin ESR, Gopal AK. Treatment strategies for Hodgkin lymphoma recurring following autologous hematopoietic stem cell transplantation. Korean J Hematol. 2012:47:8-16.

11. Ruiz-Arguelles GJ, Lopez-Martinez B, Lopez-Ariza B. Successful allogeneic stem cell transplantation with nonmyeloablative conditioning in patients with relapsed Hodgkin's disease following autologous stem cell transplantation. Arch Med Res. 2003;34:242-5.

12. Younes A, Bartlett NL, Leonard JP, Kennedy DA, Lynch CM, Sievers EL, Forero-Torres A. Brentuximab vedotin (SGN-35) for relapsed CD30-positive lymphomas. N Engl J Med. 2010;363:1812-21.

13. Younes A, Gopal AK, Smith SE, Ansell SM, Rosenblatt JD, Savage KJ, et al. Results of a pivotal phase II study of brentuximab vedotin for patients with relapsed or refractory Hodgkin's lymphoma. J Clin Oncol. 2012:30:2183-9.

14. Wang J, Yuan R, Song W, Sun J, Liu D, Li Z. PD-1, PD-L1 (B7-H1) and tumorsite immune modulation therapy: the historical perspective. J Hematol Oncol. 2017;10:34.

15. Liu B, Song Y, Liu D. Recent development in clinical applications of PD-1 and PD-L1 antibodies for cancer immunotherapy. J Hematol Oncol. 2017:10:174.

16. Bristol-Myers Squibb Company. OPDIVO (nivolumab) injection, for intravenous use. Princeton: Bristol-Myers Squibb Company; 2017.

17. Merck Sharp \& Dohme Corp. KEYTRUDA ${ }^{\circledR}$ (pembrolizumab) for injection, for intravenous use. County Cork: Merck Sharpe \& Dohme, Corp; 2017.

18. Jucker M, Sudel K, Horn S, Sickel M, Wegner W, Fiedler W, Feldman RA. Expression of a mutated form of the p85alpha regulatory subunit of phosphatidylinositol 3-kinase in a Hodgkin's lymphoma-derived cell line (CO). Leukemia. 2002;16(894-901):19.

19. Dutton A, Reynolds GM, Dawson CW, Young LS, Murray PG. Constitutive activation of phosphatidyl-inositide 3 kinase contributes to the survival 
of Hodgkin's lymphoma cells through a mechanism involving Akt kinase and mTOR. J Pathol. 2005;205:498-506.

20. Nagel S, Scherr M, Quentmeier H, Kaufmann M, Zaborski M, Drexler HG, MacLeod RAF. HLXB9 activates IL6 in Hodgkin lymphoma cell lines and is regulated by PI3 K signalling involving E2F3. Leukemia. 2005;19:841-6.

21. De J, Brown RE. Tissue-microarray based immunohistochemical analysis of survival pathways in nodular sclerosing classical Hodgkin lymphoma as compared with non-Hodgkin's lymphoma. Int J Clin Exp Med. 2010;3:55-68.

22. Yee KW, Zeng Z, Konopleva M, Verstovsek S, Ravandi F, Ferrajoli A, et al. Phase I/II study of the mammalian target of rapamycin inhibitor everolimus (RAD001) in patients with relapsed or refractory hematologic malignancies. Clin Cancer Res. 2006;12:5165-73.

23. Ghobrial IM, Gertz M, Laplant B, Camoriano J, Hayman S, Lacy M, et al. Phase II trial of the oral mammalian target of rapamycin inhibitor everolimus in relapsed or refractory Waldenstrom macroglobulinemia. J Clin Oncol. 2010;28:1408-14.

24. Jundt F, Raetzel N, Muller C, Calkhoven CF, Kley K, Mathas S, et al. A rapamycin derivative (everolimus) controls proliferation through downregulation of truncated CCAAT enhancer binding protein beta and NF-KB activity in Hodgkin and anaplastic large cell lymphomas. Blood. 2005;106:1801-7.

25. Johnston PB, Inwards DJ, Colgan JP, Laplant BR, Kabat BF, Habermann TM, et al. A phase II trial of the oral mTOR inhibitor everolimus in relapsed Hodgkin lymphoma. Am J Hematol. 2010;85(320-4):26.

26. Simon R. Optimal two-stage designs for phase II clinical trials. Control Clin Trials. 1989;10:1-10.

27. Cheson BD. The International Harmonization Project for response criteria in lymphoma clinical trials. Hematol Oncol Clin. 2007;21:841-54.

28. Gopal AK, Chen R, Smith SE, Ansell SM, Rosenblatt JD, Savage KJ, et al. Durable remissions in a pivotal phase 2 study of brentuximab vedotin in relapsed or refractory Hodgkin lymphoma. Blood. 2015;125:1236-43.
29. Cheson BD, Fisher Rl, Barrington SF, Cavalli F, Schwartz LH, Zucca E, et al. Recommendations for initial evaluation, staging, and response assessment of Hodgkin and non-Hodgkin lymphoma: the Lugano classification. J Clin Oncol. 2014;32:3059-68.

30. Porta C, Osanto S, Ravaud A, Climent MA, Vaishampayan U, White $D A$, et al. Management of adverse events associated with the use of everolimus in patients with advanced renal cell carcinoma. Eur J Cancer. 2011:47:1287-98

31. Yardley DA. Adverse event management of mTOR inhibitors during treatment of hormone receptor-positive advanced breast cancer: considerations for oncologists. Clin Breast Cancer. 2014;14:297-308.

32. Kaplan B, Qazi Y, Wellen JR. Strategies for the management of adverse events associated with mTOR inhibitors. Transplant Rev. 2014;28:126-33.

33. Younes A, Sureda A, Ben-Yehuda D, Zinzani PL, Ong TC, Prince HM, et al. Panobinostat in patients with relapsed/refractory Hodgkin's lymphoma after autologous stem-cell transplantation: results of a phase II study. J Clin Oncol. 2012;30:2197-203.

34. Rueda A, Garcia-Sanz R, Pastor M, Salar A, Labrador J, Quero-Blanco C, et al. A phase II study to evaluate lenalidomide in combination with metronomic-dose cyclophosphamide in patients with heavily pretreated classical Hodgkin lymphoma. Acta Oncol. 2015;54(933-8):35.

35. Ansell SM, Lesokhin AM, Borrello I, Halwani A, Scott EC, Gutierrez M, et al. PD-1 blockade with nivolumab in relapsed or refractory Hodgkin's lymphoma. N Engl J Med. 2015;372:311-9.

36. Rothe A, Sasse S, Topp MS, Eichenauer DA, Hummel H, Reiners KS, et al. A phase 1 study of the bispecific anti-CD30/CD16A antibody construct AFM13 in patients with relapsed or refractory Hodgkin lymphoma. Blood. 2015;125:4024-31.
Ready to submit your research? Choose BMC and benefit from:

- fast, convenient online submission

- thorough peer review by experienced researchers in your field

- rapid publication on acceptance

- support for research data, including large and complex data types

- gold Open Access which fosters wider collaboration and increased citations

- maximum visibility for your research: over 100M website views per year

At BMC, research is always in progress.

Learn more biomedcentral.com/submissions 